\title{
Grb2-Associated Binder-1 Is Required for Neuregulin-1- Induced Peripheral Nerve Myelination
}

\author{
Yoon Kyung Shin, ${ }^{1}$ So Young Jang, ${ }^{1}$ So Young Park, ${ }^{2}$ Joo Youn Park, ${ }^{1}$ Jong Kuk Kim, ${ }^{3}$ Jong Phil Kim, ${ }^{4}$ Duk Joon Suh, ${ }^{1}$ \\ Hye Jeong Lee, ${ }^{2}$ and Hwan Tae Park ${ }^{1}$ \\ ${ }^{1}$ Departments of Physiology and ${ }^{2}$ Pharmacology, and ${ }^{3}$ Mitochondria Hub Regulation Center (MHRC), Department of Neurology, College of Medicine, \\ Dong-A University, 602-714 Busan, South Korea, and ${ }^{4}$ Department of Biomedical Engineering, Dongkuk University, 100-715 Seoul, South Korea
}

Grb2-associated binders (Gabs) are scaffolding proteins implicated in cell signaling via receptor tyrosine kinases including neuregulin1(NRG1)-ErbB receptor signaling, which is essential for peripheral nerve myelination. Here, we show that the conditional removal of Gab1 from Schwann cells resulted in hypomyelination and abnormal development of Remak bundles. In contrast, hypomyelination was not observed in conventional Gab2 knock-out mice. Tyrosine phosphorylation of Gab1, but not Gab2, in sciatic nerves was upregulated during the myelination period and was found to be suppressed in NRG1-type III $(+/-)$ mice, which display a hypomyelinated phenotype similar to that observed in Gab1 knock-out mice. Gab1 knock-out and NRG1-type III $(+/-)$ mice both exhibited reduced extracellular signal-regulated kinase activity in myelinating nerves. In addition, Krox20, a transcription factor that is critical for myelination, has been identified as a target of the NRG1-Gab1 pathway during the myelination process. Our findings suggest that Gab1 is an essential component of NRG1-type III signaling during peripheral nerve development.

Key words: conditional knock-out mice; Grb2-associated binders; myelination; neuregulin; Schwann cells

\section{Introduction}

The myelination of peripheral nerves is achieved through an ensheathment process involving the extended membranes of Schwann cells (SCs) after birth, and the thickness of the myelin sheath is proportional to the axonal diameter (Pereira et al., 2012). To determine the ensheathment fates of axons and properly organize myelin sheath formation relative to axonal diameter, several molecular aspects of axon-SC interactions have been emphasized (Pereira et al., 2012). Axonal signals, such as neuregulin-1 (NRG1)-type III, determine not only the ensheathment of large axons but also the extents of myelination (Michailov et al., 2004; Taveggia et al., 2005). Extracellular signal regulated kinase (ERK)-dependent pathways have been implicated in the NRG1-induced activation of Krox20 (also known as Egr2), an essential transcription factor for the myelination of peripheral nerves (Topilko et al., 1994; He et al., 2010). It has also recently been reported that the temporal regulation of phosphoinositide 3 kinase (PI3K)-AKT activity controls myelin sheath thickness (Cotter et al., 2010). In contrast to the abundance of evidence for the roles of ERK and PI3K in myelination, the ways

Received Nov. 26, 2013; revised April 2, 2014; accepted April 25, 2014.

Author contributions: Y.K.S., S.Y.J., J.K.K., and H.T.P. designed research; Y.K.S., S.Y.J., S.Y.P., J.Y.P., and J.K.K. performed research; J.P.K., D.J.S., and H.J.L. contributed unpublished reagents/analytic tools; D.J.S. and H.T.P. analyzed data; H.T.P. wrote the paper.

This research was supported by a National Research Foundation of Korea (NRF) grant funded by the Korean government (MSIP; 2013041811, 2012-0005295). We thank Drs. Lawrence Wrabetz and M. Laura Feltri for providing MPZ-Cre and the heterozygous NRG1-type III mice. We thank Drs. Hirano and Keigo for providing the Gab1flox and Gab2 knock-out mice.

The authors declare no competing financial interests.

Correspondence should be addressed to Dr. Hwan Tae Park, 3-1, Dongdaesin-Dong, Seo-Gu, 602-714 Busan, South Korea. E-mail: phwantae@dau.ac.kr.

DOI:10.1523/JNEUROSCI.4947-13.2014

Copyright $\odot 2014$ the authors $\quad 0270-6474 / 14 / 347657-06 \$ 15.00 / 0$ in which the activities of these proteins are regulated by NRG1 in the myelinating nerves remain largely unknown.

Grb2-associated binders (Gab1-3) are scaffolding proteins involved in signal transduction of receptor tyrosine kinases and cytokine receptors (Gu and Neel, 2003). Gabs are tyrosine phosphorylated and provide a docking site for several $\mathrm{SH} 2$ domain-containing signaling proteins, such as protein tyrosine phosphatase 2 (Shp2) and PI3K-regulatory subunit p85, which activate ERK and AKT, respectively (Gu and Neel, 2003; Nishida and Hirano, 2003). Studies on Gab1-deficient mice revealed that Gab1 is essential for the development of several organs, including the heart and muscle (Itoh et al., 2000; Sachs et al., 2000). The NRG1-ErbB2 pathway also requires Gabs for the maintenance of cardiovascular systems (Nakaoka et al., 2007). Given the importance of the NRG1-ErbB2-ERK/AKT cascade in peripheral nerve myelination, we investigated the role of Gab1 and Gab2 in peripheral nerve myelination using SC-specific Gab1 knock-out mice and conventional Gab2 mice. We identified an important role of Gab1, but not Gab2, in peripheral nerve myelination. In addition, haploinsufficient NRG1-type III $(+/-)$ mice, which experience hypomyelination (Michailov et al., 2004), exhibited a decrease of Gab1 signaling in the developing sciatic nerves. Together, our findings demonstrate that Gab1 is a novel regulator of NRG1-induced peripheral nerve myelination.

\section{Materials and Methods}

Animals. Genotyping for the Gab1 locus, myelin protein zero (MPZ)-Cre transgene, and NRG1-type III mice were performed by PCR analysis of tail genomic DNA as described previously (Feltri et al., 1999; Itoh et al., 2000; Taveggia et al., 2005). Conventional Gab2 knock-out mice were obtained from RIKEN animal resources center. All surgical procedures were performed according to protocols approved by Dong-A University Committee on Animal Research, which follows the guidelines for animal experiments 
that were established by the Korean Academy of Medical Sciences. Either sex of animals was used for the following analyses.

Electron microscopy. Sciatic nerves were processed for electron microscopy (EM) as described previously (Shin et al., 2010). To measure the $g$-ratio of myelinating SCs, captured EM images $(\times 4000-5000)$ were analyzed using ImageJ software (National Institute of Health, Bethesda, MD). The $g$-ratios were determined by dividing the perimeter of the axon by that of the outer leaflet of the myelin sheath. Morphometric analyses of Remak bundle development were determined from the same images used for $g$-ratio analysis. The number of myelinated fibers in a montage consisting of $\sim 20$ photographs taken at $\times 600$ magnification using semithin sections was evaluated for each mouse $(n=3)$.

Immunofluorescence staining, Western blot analysis, and quantitative reverse transcription $P C R$. Immunofluorescence (IF) staining, Western blot analysis, and quantitative PCR (qPCR) were performed as described previously (Shin et al., 2013). The sources of antibodies and sequences of primers for qPCR are available upon request.

To quantify the number of Krox20-positive cells in cross sections stained for Krox20, 8-10 captured images $(100 \times 100 \mu \mathrm{m})$ from three independent experiments for each group were used. The number of DAPI-positive and Krox20-positive nuclei within this was counted, and the data represent the percentage of Krox20-positive cells out of the total number of DAPI-positive nuclei.

Primary SC culture, plasmids, and lentiviral infection. Primary SCs were isolated from the sciatic nerves of 4- to 5-d-old Sprague Dawley pups using a modified version of Brockes' method (Brockes et al., 1979). When the cell density reached $70 \%$ confluency, lentiviral particles expressing Gab1-shRNAi or scrambled shRNAi, which were generated using Lentiviral shRNA vectors (MISSION shRNA Lentiviral Transduction; Sigma) and packaging vectors, were administrated at various concentrations for 18-24 h. Then, the medium was replaced with fresh DMEM containing 10\% FBS and cultured for another $24 \mathrm{~h}$. For biochemical analyses, infected primary SCs were plated on 24 -well dishes at a density of $1 \times 10^{5} /$ well. The following day, the cells were starved by replacing the media with DMEM containing 0.5\% FBS. Following an overnight incubation, the cells were treated with NRG1 for the indicated times. SC lysates were prepared in boiling $2 \times$ SDS dye for Western blot analysis.

Electrophysiology. Electrophysiology was performed on the sciatic nerves of adult mice. After anesthesia, a pair of steel needle electrodes (Technomed Europe) was placed over the sciatic nerves at the sciatic notch (for proximal stimulations) or the ankle (for distal stimulations). The measurement of motor nerve conduction velocity (NCV) was performed using supramaximal stimulations of $0.01 \mathrm{~ms}$ duration using a Nicolet Viking IV. The peakto-peak amplitude and latency of CMAP were
A
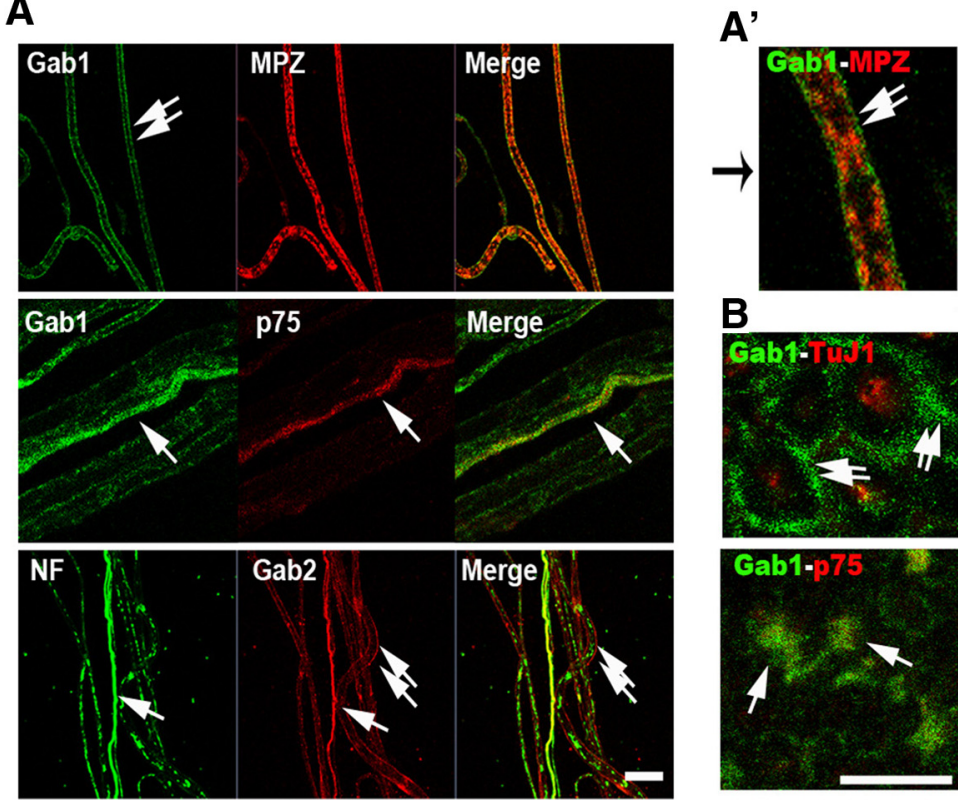

B
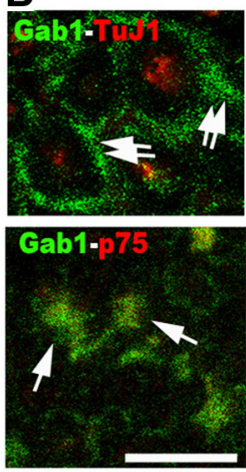

C
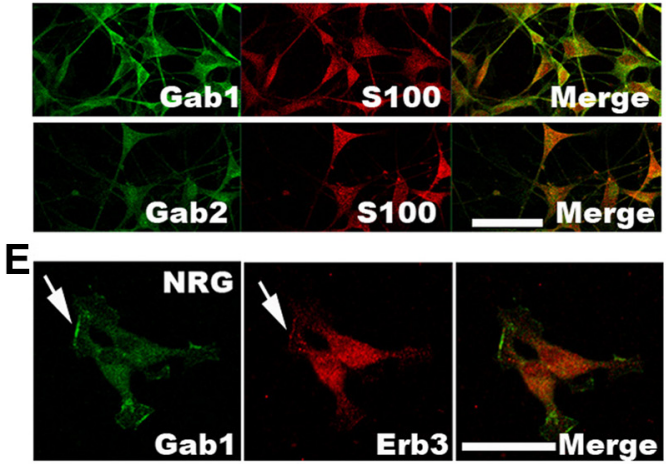

D

NRG $0102060 \mathrm{~min}$ pGab1

Gab1

Gab2

pGab2

pSGab2

actin
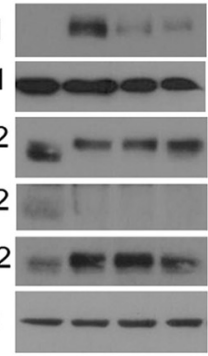

$\mathbf{F}$
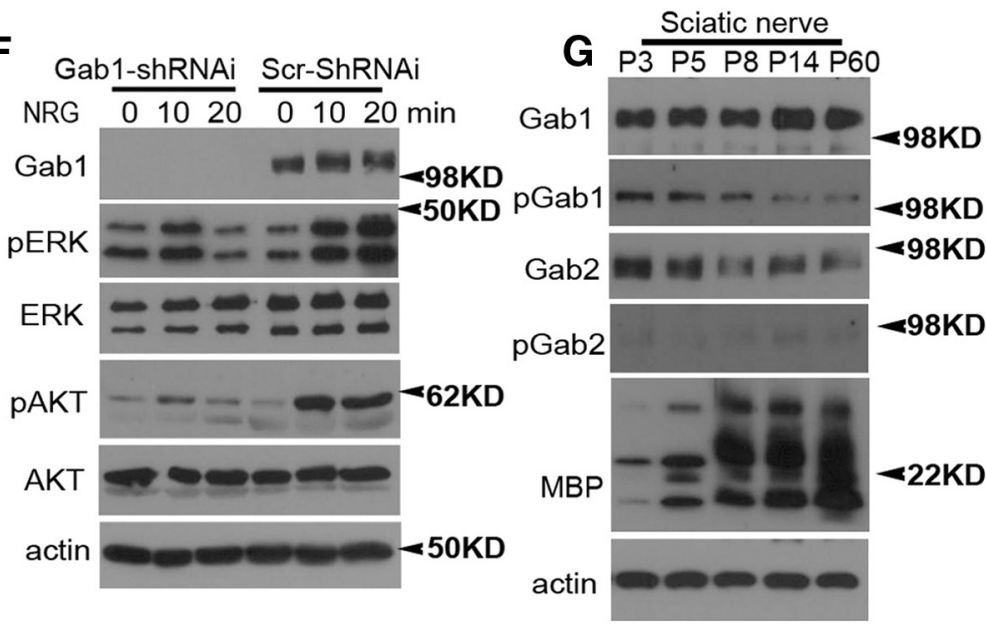

Figure 1. The expression and activation profiles of Gab1 and Gab2 in SCS. $\boldsymbol{A}, \boldsymbol{B}$, Representative IF staining against Gab1 and Gab2 in teased nerve preparations $(\boldsymbol{A})$ and cross sections $(\boldsymbol{B})$ of $\mathrm{P} 60$ sciatic nerves. Double arrows, myelinating $\mathrm{SC}$; single arrows, nonmyelinating SCs; p75, p75 neurotrophin receptor; NF, neurofilament; TuJ1, $\beta$-tubulin. $\boldsymbol{A}^{\prime}$, A magnified image. $C$, The expression of Gab1 and Gab2 in cultured SCs was identified by S100 staining. $\boldsymbol{D}$, Western blot analysis displaying NRG1-induced activation of Gab1 and Gab2 in primary SCS. $\boldsymbol{E}$, The localization of Gab1 in membrane ruffles (arrow) following NRG1 treatment for 60 min. Scale bars: $\boldsymbol{A}-\boldsymbol{C}, \boldsymbol{E}, 20 \mu \mathrm{m}$. $\boldsymbol{F}$, Western blot analysis showing the complete suppression of Gab1 expression in Gab1-silenced SCS. In contrast to the sustained activation of ERK and AKT by NRG1 ( $>20 \mathrm{~min}$ ) in scrambled (Scr)-shRNAi-infected SCs, the phosphorylation of ERK and AKT was only minimally increased by NRG1 in Gab1-shRNAi-infected SCs, and it returned to basal levels within 20 $\min$. G, Western blot analysis displaying the expression and activation profiles of Gab1 and Gab2 in developing sciatic nerves. At least three independent experiments were performed for Western blot analysis $(\mathbf{D}, \boldsymbol{F}, \boldsymbol{G})$, and representative blots were shown. 
A
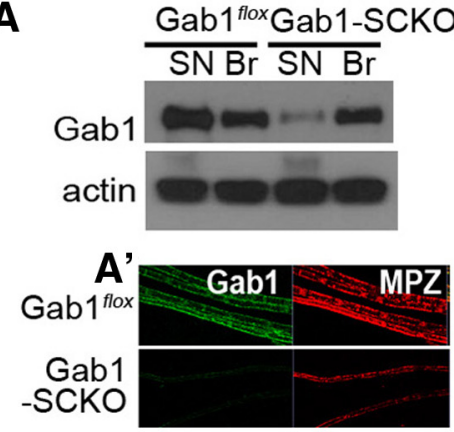

B
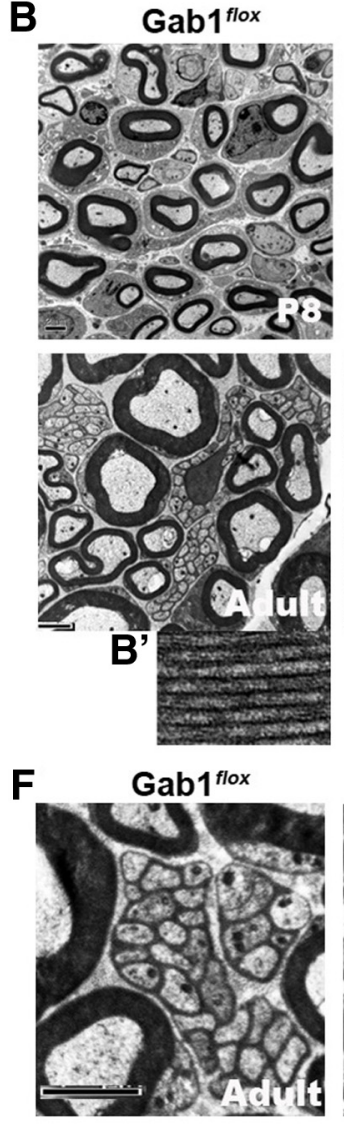

Gab1-SCKO
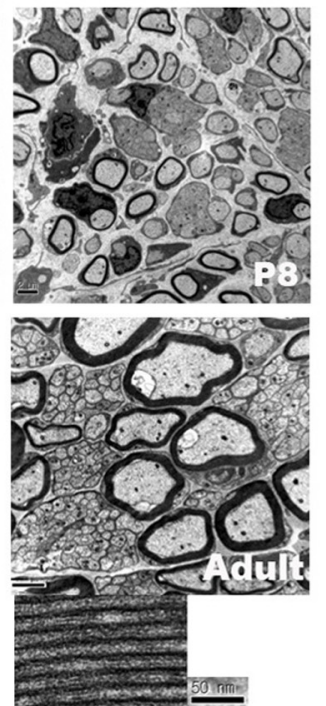

Gab1-SCKO

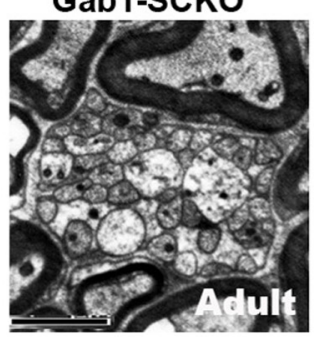

\section{C}

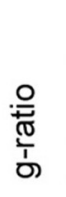

0.4

0

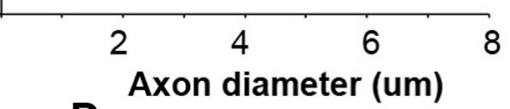

D
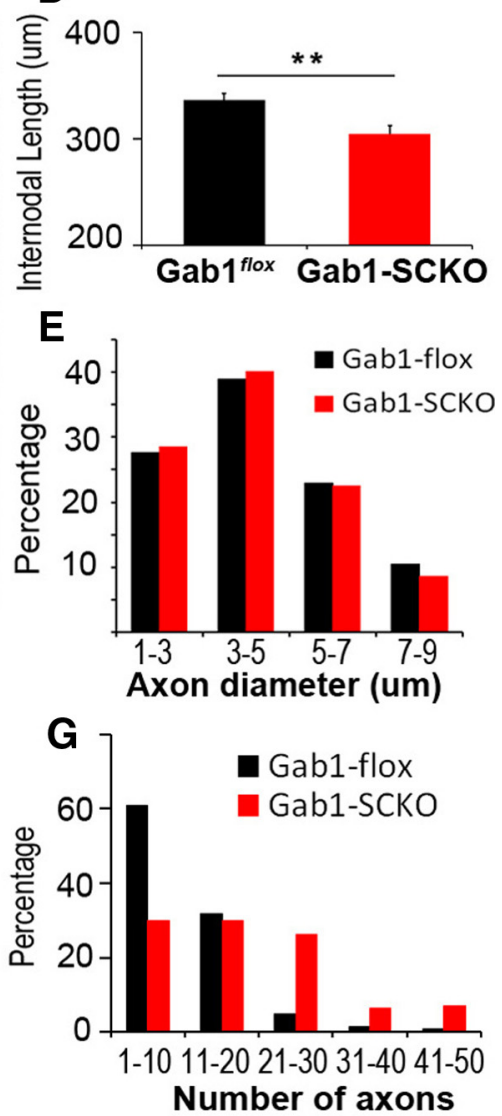

Figure 2. SC-specific knock-out of Gab1 results in hypomyelination. $\boldsymbol{A}, \boldsymbol{A}^{\prime}$, Western blot analysis $(\boldsymbol{A})$ and IF staining $\left(\boldsymbol{A}^{\prime}\right)$ displaying a reduction in Gab1 expression in the sciatic nerves (SN) of Gab1-SCKO mice, compared withGab ${ }^{\text {flox }}$ mice at P60. Br, brain. $\boldsymbol{B}$, Representative EM images of sciatic nerves from Gab1 ${ }^{\text {flox }}$ and Gab1-SCK0 mice at P8 and P60. Scale bar, $2 \mu \mathrm{m} . \boldsymbol{B}^{\prime}, A$ magnified image of myelin lamellae. Scale bar, $50 \mathrm{~nm}$. C, A scatter plot showing the $g$-ratio in relation to the axonal diameter at P60. Approximately 200 axons from two mice in each group were examined for this analysis. $\boldsymbol{D}$, The mean length of the internodes was measured using 130 teased nerve fibers in each group $(n=3)$ at P21 (mean \pm SEM). $\boldsymbol{E}$, The distribution profile of myelinated axonal diameter. $\boldsymbol{F}$, Representative EM images of unmyelinated nerve bundles. Scale bar, $2 \mu \mathrm{m}$. G, Frequency distribution profile of the number of axons per unmyelinated nerve bundle in Gab1 ${ }^{\text {flox }}$ and Gab1-SCK0 mice at P60.

recorded from foot muscles using steel electrodes. The distance between the two stimulation sites and the difference in latencies were used for calculation of NCV.

Statistical analysis. Statistical analysis was performed by using GraphPad Prism software. $P$ values were from Student's two-tailed test, and results were expressed as mean and SEM.

\section{Results}

Gab1 in SCs is responsive to NRG1 and is activated during the postnatal myelination period

To gain insight into the role of Gab1 and Gab2 in SCs, we first localized Gab1 and Gab2 expression in teased nerve preparations of adult sciatic nerves using IF staining. Both Gab1 and Gab2 were observed in the abaxonal cytoplasm of myelinating SCs (Fig. 1A). The compact myelin sheath and axoplasm, which were identified by MPZ and axonal cytoskeleton proteins (neurofilament and $\beta$-tubulin), respectively, were devoid of Gab1 and Gab2 staining. Gab1 and Gab2 were also observed in nonmyelinating SCs, which were identified by p75 neurotrophin receptor staining. Similar profiles of Gab1 and Gab2 expression in SCs were also identified by IF staining of adult sciatic nerve cross section (Fig. 1B). Consistent with the observed IF staining patterns in sciatic nerves, abundant expression of Gab1 and Gab2 was observed in the cytoplasmic region of cultured primary SCs, which were identified by $\mathrm{S} 100$ immunostaining (Fig. $1 C)$. Western blot analysis revealed that treatment of primary SCs with NRG1 (200 $\mathrm{ng} / \mathrm{ml}$ ) induced tyrosine phosphorylation of Gab1 at residue 627 (pGab1), which is indicative of Gab1 activation ( $\mathrm{Gu}$ and Neel, 2003), within $10 \mathrm{~min}$. In contrast, NRG1 did not induce tyrosine phosphorylation of Gab2 at residue 452 (pGab2; Fig. 1D). We observed a mobility shift of Gab2 in SDS-PAGE following NRG1 treatment. This shift appeared to be induced by serine phosphorylation of Gab2 (p-S-Gab2; Fig. 1D), which is not associated with Gab2 activation (Lynch and Daly, 2002). In addition, NRG1 treatment led to an increase Gab1 staining in membrane ruffles where ErbB3 was colocalized (Fig. $1 E$ ), indicating a role of Gabl as a downstream mediator of NRG-ErbB signaling in SCs.

To determine the role of Gab1 in NRG1-induced ERK/AKT activation, we silenced Gab1 expression using Gab1targeted lentiviral shRNAi in primary SCs. SCs that were infected with lentiviral Gab1-shRNAi or lentiviral scrambled shRNAi were stimulated with NRG1, and the NRG1-induced activation of ERK and AKT was then analyzed using phosphospecific antibodies. In contrast to the sustained activation of ERK and AKT, which was observed for $>20 \mathrm{~min}$ following NRG1 treatment in lentiviral scrambled shRNAi-infected SCs, NRG1-induced activation of ERK and AKT was severely abrogated in Gab1-silenced SCs (Fig. $1 F$ ).

We next examined the time course of the expression of Gab1 and Gab2 proteins in sciatic nerves during postnatal development using Western blot analysis (Fig. 1G). Gab1 expression in the sciatic nerves was detected at postnatal day 3 (P3) and was observed to increase until P14. In addition, high levels of pGab1 were observed during the first postnatal week but decreased thereafter. Gab2 protein levels were high at P3 and decreased thereafter. Tyrosine phosphorylation of Gab2 at tyrosine residue 
452 occurred at very low levels, and it was not significantly altered throughout the postnatal period. Together, these findings indicate that Gab1 may be involved in peripheral nerve myelination.

\section{Conditional removal of Gab1 from SCs} results in hypomyelination

To directly reveal the role of Gabl in peripheral nerve myelination, we generated an SC-specific conditional mutant in which floxed Gabl (Gabl ${ }^{\text {flox}}$; Itoh et al., 2000) is removed by a MPZ promoterderived Cre recombinase (Feltri et al., 1999). Because MPZ-Cre mice express Cre recombinase at approximately E14.5E15.5, the SC-specific Gabl ablation (Gab1-SCKO) that is achieved in these animals would occur before SC myelination. Gab1 deletion from the sciatic nerve was confirmed by Western blot analysis (Fig. 2A) and IF staining (Fig. 2A'). The remaining Gabl signal in Gab1-SCKO nerves that was observed by Western blot analysis might result from the expression of Gab1 in other cell types, such as endoneurial fibroblasts and vascular cells, which were not targeted by MPZ-Cre. Gab1-SCKO mice were viable and did not exhibit obvious gait abnormalities during adulthood.

To explore myelination defects, myelin sheath thickness was quantified by measuring the $g$-ratio in adulthood (P60). The $g$-ratio of axons from Gab1-SCKO mice was 0.7893 , and it was 0.703 in $\mathrm{Gab1}^{\text {flox }}$ mice, thus suggesting reduced thickness of the myelin sheath in Gab1SCKO nerves (Fig. 2 B, C). Hypomyelination was also observed in the sciatic nerves of mutant mice at P8 (Fig. 2B) and was accompanied by a decrease in the longitudinal growth of myelinating SCs, which was demonstrated by a reduced mean length of the internode (Fig. $2 D)$. However, the ultrastructural appearance of myelin lamellae (Fig. $\left.2 B^{\prime}\right)$, the mean axonal diameter $(2.94 \pm 0.009 \mu \mathrm{m}$ in $\mathrm{Gab}^{\text {flox }}$ and $3.11 \pm 0.009 \mu \mathrm{m}$ in Gab1-SCKO, $\left.p>0.05\right)$, and the distribution of axonal diameter (Fig. $2 E$ ) were unchanged, indicating that the number of spiral wrappings of myelin lamellae was reduced in the mutants.

Remak bundle morphology was also severely altered in Gab1SCKO mice compared with Gabl ${ }^{f l o x}$ control mice (Fig. 2F). Analyses of the frequency distribution of axons per unmyelinated nerve bundle revealed that more axons were associated with nonmyelinating SCs in Gab1-SCKO mice than in control mice (Fig. $2 G$ ), and the mean number of unmyelinated axons per bundle was 10.03 and 19.04 in Gab1 ${ }^{\text {flox }}$ and Gab1-SCKO mice, respectively $(p<0.01)$. In addition, many axons were directly apposed to each other and were not separated by the cytoplasm of an SC, presumably these were immature SCs that had not yet differentiated into Remak SCs (Fig. $2 F$ ). Furthermore, $\sim 50 \%$ of the bundles in Gab1-SCKO nerves contained more than one large axon $(>1 \mu \mathrm{m}$ in diameter), while only $0.5 \%$ of the Remak bundles in Gab1 $1^{\text {flox }}$ nerves contained a large axon. Consistent with this find- ing, we observed a significant reduction in the total number of myelinated fibers in Gab1-SCKO nerves compared with Gab1 ${ }^{\text {flox }}$ nerves $(3295 \pm 173$ vs $3999 \pm 205, p<0.01)$. The phenotypes described above are similar to those reported in NRG1-type III(+/-) mice (Taveggia et al., 2005). Thus our results suggest that NRG1-Gab1 signaling appears to play an important role in the completion of axonal segregation.

We next examined the functional aspect of sciatic nerve development by measuring NCV in adulthood. Motor NCV was markedly slower in Gab1-SCKO mice, compared with Gab1 ${ }^{\text {flox }}$ mice $(21.55 \pm 1.81$ vs $29.56 \pm 2.64(\mathrm{~m} / \mathrm{s}), p<0.05)$. Together, these findings suggest that Gab1 is required for proper myelination of peripheral nerves.

\section{Gab2 is not required for peripheral nerve myelination}

We next determined whether Gab2 is required for peripheral nerve myelination by examining the structures of sciatic nerves from conventional Gab2 knock-out mice (Nishida et al., 2002) via EM. The reduction in Gab2 levels in the sciatic nerves of Gab2(-I-) mice was demonstrated by Western blot analysis (see Fig. $4 D$ ). At P10 and adulthood, the degree of myelination was not altered in Gab2 $(-/-)$ mice compared with Gab2(+/-) mice as demonstrated by analyses of the $g$-ratio (Fig. $3 A-C$ ). In 
A

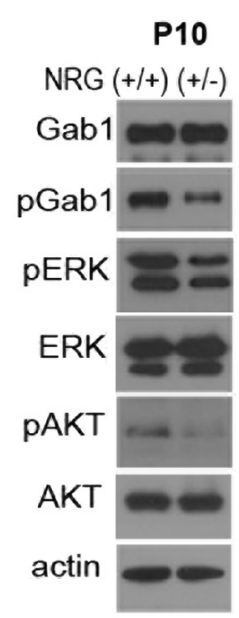

B

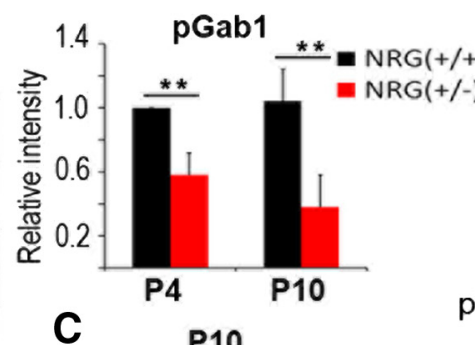

D

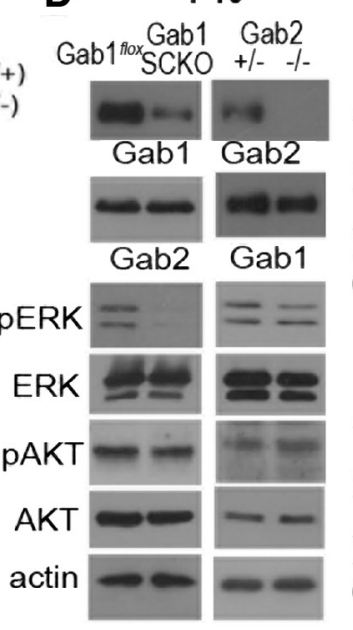

E

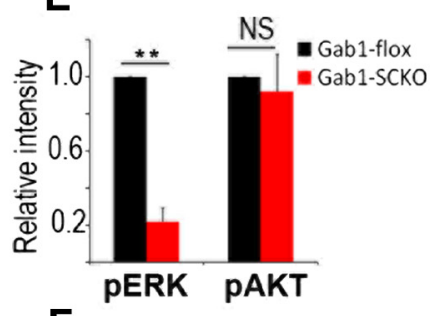

F

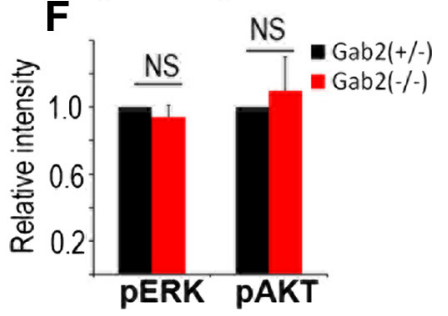

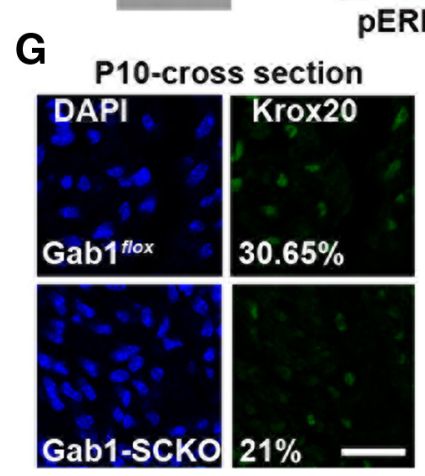

H
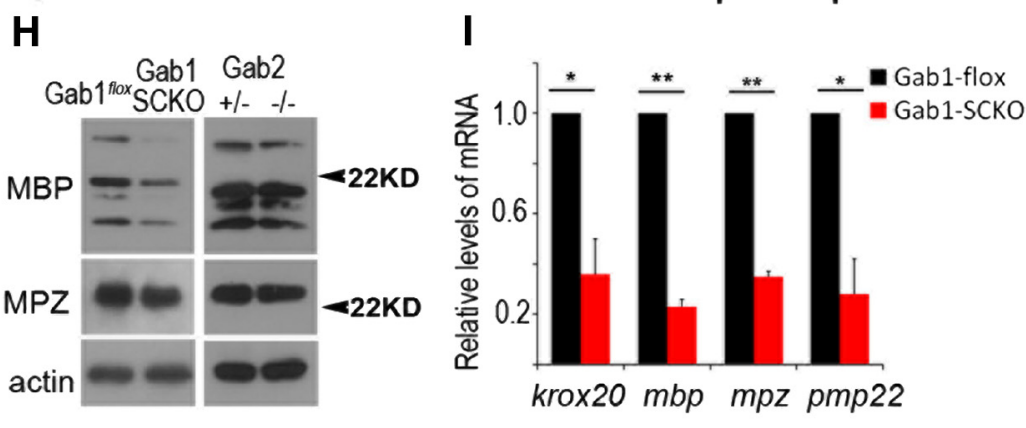

Figure 4. Role of Gab1 in NRG1-type III signaling in myelinating nerves in vivo. $\boldsymbol{A}$, Western blot analysis using sciatic nerve lysates from NRG1-type III(+ /+) and (+ / -) mice at P10. $\boldsymbol{B}, \boldsymbol{C}$, The relative levels of Gab1, ERK, and AKT phosphorylation were normalized to their respective total protein levels. For quantitative analysis, the films were scanned and the intensity was analyzed using a LAS image analysis system (Fujifilm) from three independent experiments (mean \pm SEM). D, Western blot analysis showing the levels of $p$-ERK and p-AKT in the sciatic nerves of Gab1 ${ }^{\text {flox }}$, Gab1-SCKO, Gab2 (+/-), and Gab2 (-/-) mice at P10. E, F, Quantification of the relative levels of phosphorylation of ERK and AKT ( $n=3$, mean \pm SEM). $\boldsymbol{G}$, Representative IF staining against Krox20 in cross sections of sciatic nerves at P10. Scale bar, $30 \mu \mathrm{m}$. The percentage data in the figures represent the percentage of Krox20-positive nuclei from DAPI-positive nuclei $(n=3$, mean \pm SEM). $\boldsymbol{H}$, Western blot analysis showing the expression levels of MBP and MPZ in sciatic nerves at P10. Representative blots from three independent experiments were shown. $\boldsymbol{I}, \mathrm{qPCR}$ analysis revealed a reduction in krox20, mbp, $m p z$, and pmp22 mRNA levels in Gab1-SCKO nerves compared withGab1 ${ }^{\text {flox }}$ nerves $\left(n=3\right.$, mean \pm SEM); ${ }^{*} p<0.05$, ${ }^{* *} p<0.01$.

addition, the morphology of Remak bundles and the development of unmyelinated axons were also normal in the mutants (Fig. 3D). The NCV of the sciatic nerves of Gab2 $(-/-)$ mice was not significantly different from that observed in Gab2(+/-) mice $[31.43 \pm 1.75$ vs $29 \pm 2.42(\mathrm{~m} / \mathrm{s}), p>0.05]$.

Gab1 mediates NRG1 signaling in myelinating nerves in vivo We next examined whether NRG1 is responsible for Gab1 activation in developing sciatic nerve in vivo. NRG1-type III knockout mice are embryonic lethal, but NRG1-type III (+/-) mice are viable and exhibit a hypomyelinated phenotype in the peripheral nerves (Michailov et al., 2004). Western blot analysis of lysates from developing sciatic nerves at P4 and P10 revealed a significant decrease in the level of pGab1 in NRG1-type III $(+/-)$ mice, compared with NRG1-type III(+/+) control mice (Fig. 4A,B). We also found a significant reduction in the phosphorylation levels of ERK and AKT in nerves from NRG1-type III $(+/-)$ mice (Fig. $4 A, C$ ).

To directly reveal the role of Gabl in ERK/AKT activation in myelinating nerves in vivo, we performed Western blot analyses using sciatic nerve lysates from Gab1 ${ }^{\text {flox }}$ and Gab1-SCKO mice at P10 (Fig. 4D-F). The phosphorylation levels of ERK, but not AKT, were significantly reduced in Gab1-SCKO nerves compared with Gab1 ${ }^{\text {flox }}$ nerves (Fig. $4 D, E$ ). However, the phosphorylation levels of ERK and AKT in the sciatic nerves of Gab2(-/-) mice were not significantly reduced compared withGab2 $(+/-)$ mice (Fig. 4D,F).Together, these findings indicate that the NRG1-Gab1-ERK pathway might be involved in peripheral nerve myelination.

It has been shown that NRG1 signaling regulates postnatal myelination in part via the activation of Krox20 (Kao et al., 2009; He et al., 2010). Thus, we examined the expression levels of Krox20 protein in the sciatic nerves of Gab1-SCKO and Gab1 ${ }^{\text {flox }}$ mice (Fig. 4G). The levels of Krox20 expression in Gab1-SCKO nerves were significantly lower than that observed in control nerves at P10, as demonstrated by the reduced number of Krox 20 -immunoreactive nuclei $(21 \pm 1.46 \%$ vs $30.65 \pm 1.55 \%$, $p<0.05)$. This decrease in the level of Krox20 expression was accompanied by a reduction in krox20 transcription as measured using qPCR analysis of sciatic nerve RNA (Fig. 4I). The expression of myelin proteins that are regulated by Krox 20 activity, such as MPZ and myelin basic protein (MBP; Kao et al., 2009; He et al., 2010), was also decreased in the sciatic nerves of Gab1-SCKO mice compared with Gab1 ${ }^{\text {flox }}$ mice (Fig. $4 H$ ). qPCR analysis confirmed the decrease in the mRNA expression of the major myelin genes, $m b p$, $m p z$, and $p m p 22$, in the mutant nerves (Fig. $4 I$ ). In contrast to these findings, the expression levels of myelin proteins in Gab2(-/-) nerves were similar to those observed in Gab2(+/-) nerves (Fig. $4 H)$. 


\section{Discussion}

Here we have provided several lines of evidence for the specific role of Gab1 in translating the intensity of NRG1 signaling on axonal surface to the thickness of the myelin sheath for peripheral nerve myelination. The activation profile of Gab1 parallels the myelination period. Consistent with this observation, the genetic removal of Gab1 in SCs resulted in defective longitudinal and radial growth of the myelin sheath. Notably, the phosphorylation levels of Gab1 during the myelination period decreased significantly in NRG1-type III $(+/-)$ nerves. Finally, the deletion of Gab1 from SCs abrogated ERK-mediated, but not AKTmediated, myelin gene expression. A recent report has shown that the myelination phenotypes of ERK1/2(-/-) and NRG1type III $(+/-)$ mutant mice are strikingly similar (Newbern et al., 2011). Thus, we conclude that the NRG1-Gab1-ERK cascade participates in the control of myelin sheath thickness in part by regulating the expression of myelin-related proteins. Because phosphorylated Gab1 provides docking sites for Shp2, an upstream mediator of ERK activation in a variety of cells (Cai et al., 2002; Gu and Neel, 2003), Gab1-Shp2 interactions may be responsible for ERK activation and myelination. Indeed, the sciatic nerves of Shp 2 mutant mice are characterized by hypomyelinated phenotypes and decreased ERK activation (Grossmann et al., 2009). In contrast to the Gab1-dependent ERK activation in myelinating nerves in vivo, AKT activation was not significantly altered in the Gab1-SCKO. It appears that NRG1-Gab1 signaling might not be responsible for the activation of AKT in myelinating nerves in vivo or that multiple factors, including NRG1, may regulate $\mathrm{AKT}$ with differential temporal dynamics during the myelination period.

In addition to the role of Gab1 in myelination, Gab1 and Gab2 may also participate in SC dedifferentiation and remyelination following nerve injury because both processes appear to require NRG1-ERK signaling (Guertin et al., 2005; Napoli et al., 2012; Shin et al., 2013; Stassart et al., 2013). In particular, it has been recently demonstrated that the postinjury induction of NRG1type I in SCs is essential for peripheral nerve remyelination during nerve repair (Stassart et al., 2013). Thus, a role of Gab1 and/or Gab2 in NRG1-type I signaling during remyelination might be expected. Further studies examining the roles of Gabs in SC physiology will provide insight into the molecular mechanisms underlying peripheral nerve development and repair.

\section{References}

Brockes JP, Fields KL, Raff MC (1979) Studies on cultured rat Schwann cells. I. Establishment of purified populations from cultures of peripheral nerve. Brain Res 165:105-118. CrossRef Medline

Cai T, Nishida K, Hirano T, Khavari PA (2002) Gab1 and SHP-2 promote Ras/MAPK regulation of epidermal growth and differentiation. J Cell Biol 159:103-112. CrossRef Medline

Cotter L, Ozçelik M, Jacob C, Pereira JA, Locher V, Baumann R, Relvas JB, Suter U, Tricaud N (2010) Dlg1-PTEN interaction regulates myelin thickness to prevent damaging peripheral nerve overmyelination. Science 328:1415-1418. CrossRef Medline

Feltri ML, D’Antonio M, Previtali S, Fasolini M, Messing A, Wrabetz L (1999) P0-Cre transgenic mice for inactivation of adhesion molecules in Schwann cells. Ann N Y Acad Sci 883:116-123. CrossRef Medline

Grossmann KS, Wende H, Paul FE, Cheret C, Garratt AN, Zurborg S, Feinberg K, Besser D, Schulz H, Peles E, Selbach M, Birchmeier W, Birchmeier C (2009) The tyrosine phosphatase Shp2 (PTPN11) directs Neuregulin1/ErbB signaling throughout Schwann cell development. Proc Natl Acad Sci U S A 106:16704-16709. CrossRef Medline
Gu H, Neel BG (2003) The "Gab" in signal transduction. Trends Cell Biol 13:122-130. CrossRef Medline

Guertin AD, Zhang DP, Mak KS, Alberta JA, Kim HA (2005) Microanatomy of axon/glial signaling during Wallerian degeneration. J Neurosci 25: 3478-3487. CrossRef Medline

He Y, Kim JY, Dupree J, Tewari A, Melendez-Vasquez C, Svaren J, Casaccia P (2010) Yyl as a molecular link between neuregulin and transcriptional modulation of peripheral myelination. Nat Neurosci 13:1472-1480. CrossRef Medline

Itoh M, Yoshida Y, Nishida K, Narimatsu M, Hibi M, Hirano T (2000) Role of Gab1 in heart, placenta, and skin development and growth factor- and cytokine-induced extracellular signal-regulated kinase mitogen-activated protein kinase activation. Mol Cell Biol 20:3695-3704. CrossRef Medline

Kao SC, Wu H, Xie J, Chang CP, Ranish JA, Graef IA, Crabtree GR (2009) Calcineurin/NFAT signaling is required for neuregulin-regulated Schwann cell differentiation. Science 323:651-654. CrossRef Medline

Lynch DK, Daly RJ (2002) PKB-mediated negative feedback tightly regulates mitogenic signalling via Gab2. EMBO J 21:72-82. CrossRef Medline

Michailov GV, Sereda MW, Brinkmann BG, Fischer TM, Haug B, Birchmeier C, Role L, Lai C, Schwab MH, Nave KA (2004) Axonal neuregulin-1 regulates myelin sheath thickness. Science 304:700-703. CrossRef Medline

Nakaoka Y, Nishida K, Narimatsu M, Kamiya A, Minami T, Sawa H, Okawa K, Fujio Y, Koyama T, Maeda M, Sone M, Yamasaki S, Arai Y, Koh GY, Kodama T, Hirota H, Otsu K, Hirano T, Mochizuki N (2007) Gab family proteins are essential for postnatal maintenance of cardiac function via neuregulin-1/ErbB signaling. J Clin Invest 117:1771-1781. CrossRef Medline

Napoli I, Noon LA, Ribeiro S, Kerai AP, Parrinello S, Rosenberg LH, Collins MJ, Harrisingh MC, White IJ, Woodhoo A, Lloyd AC (2012) A central role for the ERK-signaling pathway in controlling Schwann cell plasticity and peripheral nerve regeneration in vivo. Neuron 73:729-742. CrossRef Medline

Newbern JM, Li X, Shoemaker SE, Zhou J, Zhong J, Wu Y, Bonder D, Hollenback S, Coppola G, Geschwind DH, Landreth GE, Snider WD (2011) Specific functions for ERK/MAPK signaling during PNS development. Neuron 69:91-105. CrossRef Medline

Nishida K, Hirano T (2003) The role of Gab family scaffolding adapter proteins in the signal transduction of cytokine and growth factor receptors. Cancer Sci 94:1029-1033. CrossRef Medline

Nishida K, Wang L, Morii E, Park SJ, Narimatsu M, Itoh S, Yamasaki S, Fujishima M, Ishihara K, Hibi M, Kitamura Y, Hirano T (2002) Requirement of Gab2 for mast cell development and KitL/c-Kit signaling. Blood 99:1866-1869. CrossRef Medline

Pereira JA, Lebrun-Julien F, Suter U (2012) Molecular mechanisms regulating myelination in the peripheral nervous system. Trends Neurosci 35: 123-134. CrossRef Medline

Sachs M, Brohmann H, Zechner D, Muller T, Hülsken J, Walther I, Schaeper U, Birchmeier C, Birchmeier W (2000) Essential role of Gabl for signaling by the c-Met receptor in vivo. J Cell Biol 150:1375-1384. CrossRef Medline

Shin YK, Jang SY, Lee HK, Jung J, Suh DJ, Seo SY, Park HT (2010) Pathological adaptive responses of Schwann cells to endoplasmic reticulum stress in bortezomib-induced peripheral neuropathy. Glia 58:1961-1976. CrossRef Medline

Shin YK, Jang SY, Park JY, Park SY, Lee HJ, Suh DJ, Park HT (2013) The Neuregulin-Rac-MKK7 pathway regulates antagonistic c-jun/Krox20 expression in Schwann cell dedifferentiation. Glia 61:892-904. CrossRef Medline

Stassart RM, Fledrich R, Velanac V, Brinkmann BG, Schwab MH, Meijer D, Sereda MW, Nave KA (2013) A role for Schwann cell-derived neuregulin-1 in remyelination. Nat Neurosci 16:48-54. CrossRef Medline

Taveggia C, Zanazzi G, Petrylak A, Yano H, Rosenbluth J, Einheber S, Xu X, Esper RM, Loeb JA, Shrager P, Chao MV, Falls DL, Role L, Salzer JL (2005) Neuregulin-1 type III determines the ensheathment fate of axons. Neuron 47:681-694. CrossRef Medline

Topilko P, Schneider-Maunoury S, Levi G, Baron-Van Evercooren A, Chennoufi AB, Seitanidou T, Babinet C, Charnay P (1994) Krox-20 controls myelination in the peripheral nervous system. Nature 371:796-799. CrossRef Medline 